\title{
Social networks, cultural orientations and e-government adoption behavior: A Fijian study
}

\author{
Fang Zhao ${ }^{\mathrm{a}, *}$, Suwastika Naidu ${ }^{\mathrm{b}}$, Anand Chand ${ }^{\mathrm{b}}$, Gurmeet Singh $^{\mathrm{b}}$, Aarti Sewak ${ }^{\mathrm{c}}$ and \\ Maureen Karan ${ }^{b}$ \\ ${ }^{a}$ Edith Cowan University, Perth, Australia \\ ${ }^{\mathrm{b}}$ The University of the South Pacific, Suva, Fiji \\ ${ }^{\mathrm{c}}$ Deakin University, Melbourne, Australia
}

\begin{abstract}
Research demonstrates that social networks have an intrinsic relationship with culture. However, very limited research - theoretical or empirical - has examined how social networks, along with cultural orientations, influence e-government adoption. In this paper we seek to address the gap. Based on social network theory, as well as the culture models of Hofstede (2001) and House et al. (2004), we develop a research model to study the relationships between social networks, cultural orientations and e-government adoption behavior. We then test the model empirically by means of a survey in Fiji where community-based social networks are an integral part of people's lives. Our results demonstrate in detail how social networks and cultural orientations influence e-government adoption. The theoretical and practical implications of the study are discussed.
\end{abstract}

Keywords: Social networks, cultural orientations, e-government adoption, Fiji

\section{Introduction}

The World Bank (2008) has defined 'e-government' as the use by government agencies of information technologies to transform relations with citizens, businesses, and other arms of government. However, the rate of adoption of e-government by citizens remains low in many countries (e.g. United Nations, 2016; Adu et al., 2017), which implies a significant waste of government resources and taxpayers' money.

Research by scholars has been undertaken to address the issue of the slow rate of adoption of egovernment through examining e-government adoption behavior (e.g., Bélanger \& Carter, 2012; Kurfali et al., 2017) from different theoretical perspectives: building on Rogers' (1995) diffusion of innovation theory; using various technology acceptance models (TAMs) (e.g., Davis, 1989; Venkatesh et al., 2013); and using sociotechnical theories (e.g., Fountain, 2001, 2005). Some research has attempted to study e-government adoption from a cultural perspective drawing on cultural orientation theories such as Hofstede (2001) and the GLOBE project (2004) (e.g., Zhao et al., 2014; Kurfali et al., 2017). Some research has taken a more integrative approach by combining TAMs or the unified theory of acceptance and use of

\footnotetext{
${ }^{*}$ Corresponding author: Fang Zhao, School of Business and Law, Edith Cowan University, Perth, Australia. E-mail: f.zhao@ecu.edu.au.
} 
technology (UTAUT) model with cultural theories and other constructs to examine various factors that may determine the adoption of e-government services. For example, Al-Hujran et al. (2015) incorporates TAM constructs and a set of social, political, and cultural constructs to study citizens' intention to use e-government services in Jordan and find empirically that e-government adoption is affected by multiplex factors that are often interrelated. Likewise, the study of Rabaa'I (2017) uses the UTAUT model to investigate the adoption of e-government. The UTAUT model unified and integrated key elements from eight technology adoption models and theories. The UTAUT measures four key constructs: performance expectancy, effort expectancy, social influence, and facilitating conditions (Venkatesh et al., 2013). Among the four constructs, social influence, referring to the degree to which an individual perceives that others believe he or she should use a particular system, has a special relevance to our study as we seek to investigate the influences of social networks and cultural orientations on e-government adoption. However, compared with various technology adoption models such as TAM and UTAUT, we consider that social network theory is more closely related to the context and purpose of our study.

Research has demonstrated that social networks have an intrinsic relationship with culture in terms of formation and structure. Emirbayer and Goodwin (1994) observed that 'culture and social relations empirically interpenetrate with and mutually condition one another so thoroughly that it is well-nigh impossible to conceive of the one without the other.' For example, the study of Lal (2013) suggests that social networks are often formed by people who share similar cultural norms and beliefs. A review of literature conducted by Pachucki and Breiger (2010) concluded that the boundary between studies of culture and research on social networks is increasingly blurring. They also argued that a cultural perspective complements the social network approach, thereby opening up a new path beyond network structural analysis. From a socio-cognitive perspective, studies also suggest that social networks may influence e-government adoption behavior. In this regard, the study of Alomari et al. (2014) indicates that 'word of mouth' is an important factor in the adoption of e-government within a social network or a community, especially in less developed countries where Internet access is not readily available. This is particularly the case in Pacific Island countries (PICs) where geographic isolation and dispersion as well as traditional rural and village living make community-based social networks indispensable, forming an integrated part of people's life. Like other PICs, Fiji is still a community-based society in which social networks formed by nuclear and extended families, kinships, villages, clans, and friendships are often marked and bonded by shared cultures (Lal, 2013). Costello et al. (2005) postulated that today's information society is a network society and the networks themselves reflect distinctive cultures. However, based on the comprehensive literature reviews on e-government research conducted by Yildiz (2007); Bélanger and Carter (2012) and Zhang et al. (2008) it was found that very limited research - theoretical or empirical - has studied the relationships between social networks, cultural orientations and e-government adoption behavior. To address this knowledge gap, we seek to investigate whether and how social networks and cultural orientations influence e-government adoption behavior. In this way, our study extends existing culture-e-government adoption research. More broadly, we contend that an empirical study from both social network and cultural orientation perspectives will improve our understanding of e-government adoption behavior.

To this end, we conducted empirical research in Fiji because it is one of the larger PICs, possesses the most developed economy in the South Pacific, and was ranked highest by the United Nations (2016) for e-government development in the region. This means that the findings of this study should have wider implications for the South Pacific region and other developing countries with similar cultural and social background as that of Fiji. The findings of this study are expected to inform policy-makers about the relationships between social networks and cultural orientations as well as their influence on 
e-government adoption behavior. The findings from this study should also contribute to the theoretical development of a new model for further e-government adoption research.

The next two sections discuss briefly the theoretical premises underpinning this study: social network theory and Hofstede (2001) and GLOBE cultural models (2004) and develop hypotheses and our research model. After that, we describe in detail our research methods, and then present and discuss the results. Finally, we justify this study by pinpointing its theoretical contributions and practical implications as well as identifying its limitations and areas for future research.

\section{Theories and frameworks}

\subsection{Social network theory}

Social network theory has been widely used in many disciplines to explain the connections and relationships in a social structure (Howard \& McKim, 1983; Kadushin, 2012; Wall et al., 2003). Social network theory was initially developed by the sociologists Georg Simmel and Jacob Moreno in the 1930s (Simmel, 2009; Fountain, 2005), and influenced by graph theory, sociometry, sociology and anthropology (Borgatti \& Halgin, 2011). Scott (2012) categorizes the development of social network theory into three lines of inquiry: the sociometric analysis drawing on graph theory methods from mathematics; the interpersonal relation perspective, focusing on the formation of cliques and groups; and an anthropology perspective exploring the structure of community relations. From a social science perspective, a social network is a structure and a generic mode in which a group of actors are connected by a set of social relationships, ties, or a specified type of ties (Morgan \& Rytina, 1977; Wasserman \& Faust, 1994). There are three sets of properties of networks that are of particular interest to researchers - transactional content, nature of the links, and structural characteristics (Simmel, 2009). The transactional content often refers to the exchange of information between two or more actors in social networks, while nature of the link refers to the strength and qualitative nature of the relationships between actors. Some links or ties may be stronger than others, and some may be unidirectional and others bidirectional (Sivakumar \& Nakata, 2001). The structural characteristics concern the overall pattern of relationships in social networks such as network density, clustering, and locations of nodes. Social network analysis, as a methodology and a tool, is often used to identify and evaluate in a systematic way the structural properties of social networks and display their patterns with sociograms (Sivakumar \& Nakata, 2001). While initially developed by mathematicians to visualize and investigate social structures and relations (Maertens \& Barrett, 2013), social network analysis has been increasingly used to enhance the understanding of behavioral and social phenomena of social networks (Freeman, 2004; Phillips et al., 2005). In this regard, social network can be viewed as a sociological construct and a mathematical object.

In our study, we view social networks as a sociological construct rather than a mathematical object, because we are more interested in the relational states and relational events of social networks than the formation of the social networks. Relational states refer to the various relational ties such as kinship ties, cognitive relations (e.g. knows the skills of) and affective relations (e.g. likes and dislikes), while relational events have a transactional nature, referring to social interactions such as exchange of information and giving advice (Borgatti \& Halgin, 2011). Some research has been conducted to examine the quality of the constituent ties, such as their frequency, intensity, and multiplicity (Adler \& Kwon, 2002). Other research examines the dynamic social cognition mechanisms in which individuals influence one another and, through social learning, revise their positions on issues about which they are concerned (Kane et al., 2014; Valente, 1996). Given the purpose of our study, we focus primarily on the social cognition 
that is derived from the social interactions in social networks, investigating how network ties in social networks influence e-government adoption behavior in terms of knowledge sharing and exchange, and trust. Social network research shows that information seeking and learning is one of the most important activities in social networks (Borgatti \& Cross, 2003). In this regard, we examine how information exchanges occur among social network members concerning Internet use and online trust in relation to e-government adoption. Although social networks can develop at individual, institutional and societal levels (Hill et al., 2008), we limit our Fijian survey and study to the individual level of social networks only (i.e. personal networks - families and friends), because we posit that these networks have stronger influence on members' adoption behavior than others in terms of the frequency and intensity of their connections.

\subsection{Hofstede and GLOBE cultural models}

Hofstede (2001) defines culture as 'the collective programming of the mind which distinguishes the members of one group or category of people from another. A number of sophisticated models have been developed to analyze cultural differences (e.g. Douglas, 1978; Hofstede, 2001; House et al., 2004; Inglehart \& Welzel, 2005; Trompenaars \& Hampden-Turner, 2000), of which the models of Hofstede and House and colleagues are the most influential in the extant literature.

Hofstede (2001) in a seminal empirical study of IBM employees in 40 countries during the 1960s and 1970s, identified four 'cultural orientations': power distance (PD), uncertainty avoidance (UA), individualism versus collectivism (IDV), and masculinity versus femininity (MAS). A fifth dimension long-term versus short-term orientation (LTO) - was added, following a 1991 study by Michael Bond and colleagues of students in 23 countries (Hofstede et al., 2010). In 2010, a sixth orientation was added to Hofstede's model - indulgence versus restraint - based on the work of the sociologist Minkov and his extensive World Values Survey (Hofstede et al., 2010). For the present study, we utilize all of Hofstede's cultural orientations except for the sixth, which we considered less relevant to e-government adoption. Appendix 2 summarizes the definitions of the cultural orientations. It should be noted that Hofstede's conceptualization of culture has been criticized as too simplistic because it ignores the existence of extensive within-country cultural heterogeneity (Scott, 2012; Jones, 2007) and assumes that culture is static over time (Ford et al., 2009). Several recent studies replicating Hofstede's model found that significant changes have occurred in the index scores since Hofstede's surveys, which indicates that culture is not static and changes over time (Abdullah et al., 2008). It is also noted that Hofstede's cultural conceptualization was based primarily on the cultural indexes that were generated mainly in the 1960s and 1970s. To address these issues, we took into consideration of the existence of intra-cultural differences within a nation's culture (Tung \& Verbeke, 2010) in our survey in Fiji and conducted the survey recently, instead of using Hofstede's cultural index scores.

The Global Leadership and Organizational Behavior Effectiveness (GLOBE) research program conducted by House and his team (2004) assessed cultural orientations in 62 societies, as well as the interacting effect of cultural orientations and industry on organizational practices and inherent theories of leadership. The project used two sets of indicators - cultural values and cultural practices - to measure nine orientations of national culture: uncertainty avoidance, power distance, societal collectivism, in-group collectivism, assertiveness, gender egalitarianism, performance orientation, future orientation, and human orientation. When measuring 'performance orientation', for example, the GLOBE questionnaire item for cultural practices was 'Students are encouraged to strive for continuously improved performance,' whereas the questionnaire item for cultural values was 'Students should be encouraged to strive for continuously improved performance.' For our study, we adopted GLOBE's societal cultural 


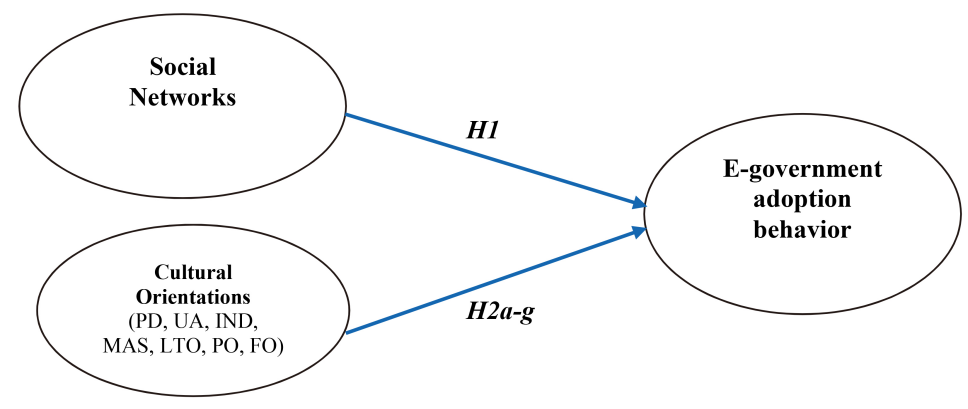

Fig. 1. Research model.

practice construct - that is, respondents' perceptions of current practices of specific cultures - because it permitted us to focus on people's behavior in relation to e-government adoption.

The GLOBE model offers several additional cultural orientations to those identified in Hofstede's model. Earlier research suggests that performance orientation (PO) and future orientation (FO) from the Globe model are associated positively with e-government development, suggesting that nations with higher PO and FO cultural orientations are more likely to embrace e-government than those with lower PO and FO (Kurfali et al., 2017; Zhao et al., 2014). By using these additional GLOBE cultural orientations, we should be able to measure cultural orientations more comprehensively than by using Hofstede's five cultural orientations alone. Based on this analysis and our experience we have added Globe's performance orientation (PO) and future orientation (FO) to the five cultural orientations listed above from Hofstede's model for use in the present study in order to apply the most relevant cultural orientation factors affecting e-government adoption by Fijian citizens.

\section{Hypothesis development}

Grounded in social network theory and the cultural models discussed in the preceding section, we developed a research model to examine the relationships between social networks and e-government adoption behavior, and between cultural orientations and e-government adoption behavior. Figure 1 illustrates this model (with $\mathrm{H}$ representing the hypotheses developed and explained below).

\subsection{Social networks and e-government adoption behavior}

According to social network theory, attitude changes in innovation diffusion occur in a social network of endogenous interpersonal influences (Burt, 1987). For example, a study by Hill et al. (2008) concluded that the social relationships of older citizens influenced their adoption of the Internet. Likewise, Chow and Chan (2008) found that social networks affected knowledge sharing and new technology adoption. Their empirical testing confirmed that a social network and shared goals significantly contributed to a person's willingness to share knowledge. The results of the studies conducted by Axford and Huggins (2003) and Jaeger and Bertot (2010) suggest that the perceptions of an individual's friends and family about e-government services may influence that person's adoption behavior due to the relational ties. An empirical study completed by Vicente and Novo (2014) highlighted the increasing importance of online social networks as catalysts for citizens' e-participation (i.e., e-government participation). Frambach and Schillewaert (2002) found that social networks could also influence people's trust, which was identified as one of the significant determinants of e-government adoption (Cato, 1955). 
In the present study, we propose to investigate whether social networks (in this paper referring to the social networks comprising an individual's families and friends) have a significant impact on egovernment adoption behavior. The results are expected to provide insight into how social networks influence e-government adoption behavior, and thus improve our understanding of whether e-government adoption could be a social interaction process within a social network. We therefore propose hypothesis H1 as follows:

H1. Social networks influence e-government adoption behavior through knowledge sharing and exchange within the networks.

\subsection{Cultural orientations and e-government adoption}

As shown in this paper, empirical research addressing the effects of culture on e-government adoption is growing, because, if the effects are proved to be significant, e-government suppliers need to consider cultural factors when designing e-government services. The majority of studies that have been published to date (e.g., Aykut, 2007; Khalil, 2011) typically have adopted the generic cultural model developed by Hofstede (2001) or the GLOBE program's cultural dimensions (House et al., 2004). For example, drawing on Hofstede's model, Aykut's (2007) study of 26 European countries found that national culture explained differences in the level of e-government adoption; specifically, countries with higher PD or higher UA cultures tended to have a lower e-government adoption rate. The reason for this outcome could be explained by some of technology diffusion studies. According to these studies, technology adoption is most likely to occur in countries that are high on individualism, low on uncertainty avoidance, and low on power distance (e.g. Zhang \& Maruping, 2008). On the other hand, countries with high IDV and/or LTO cultures were more willing to adopt e-government than were countries with collectivism or short-term orientation cultures. Adopting the GLOBE model, Khalil (2011) found that PO, UA, gender egalitarianism, and collectivism affected a nation's e-government readiness. Similarly, Zhao (2013) based on a multiple regression analysis of data from 84 countries, found that some cultural orientations - namely, IDV, PD, and LTO - significantly influenced e-government development. In terms of Masculinity/Femininity (MAS) cultural orientation, the empirical study of Khalil (2011) found that MAS has a significant impact on e-government adoption. According to Hofstede (2001), a high MAS index indicates a culture that values masculinity and may have a high expectation for performance and success.

Drawing on these studies, we hypothesize as follows:

H2a: Power distance (PD) cultural orientation will affect e-government adoption behavior.

H2b: Uncertainty avoidance (UA) will affect e-government adoption behavior.

H2c: Individualism (IND) will affect e-government adoption behavior.

H2d: Masculinity (MAS) will affect e-government adoption behavior.

H2e: Long-term orientation (LTO) will affect e-government adoption behavior.

H2f: Performance orientation (PO) will affect e-government adoption behavior.

H2g: Future orientation (FO) will affect e-government adoption behavior.

\section{Methodology}

\subsection{Survey}

To test our research model (see Fig. 1), we conducted a survey in Fiji during October and November 
2014. The survey instrument, a questionnaire, was designed to test hypotheses $\mathrm{H} 1$ and H2a-g described in the preceding sections. The questionnaire consisted of four parts: Part 1 collected demographic information about each participant, including gender, age, ethnic background, education, and occupation; Part 2 sought to identify the influence of social networks on participants; Part 3 examined the cultural orientations of each participant; and Part 4 surveyed the e-government adoption behavioral patterns of each participant. We developed the survey questionnaire drawing on established theories (i.e. social network theory) to test the role of social networks; the widely-adopted survey instruments of Hofstede (2001) and House et al. (2004) to test cultural orientations; and the popular instruments of Chuang et al. (2015) and Jaeger and Bertot (2011) to examine e-government use pattern.

To survey the role and influence of social networks (i.e., families and friends) in regards to egovernment adoption behavior, we developed our own instrument, based on the social network concept, in particular, the social cognitive perspective in which individuals influence and learn from one another, and reposition themselves through the social learning process (Khalil, 2011). We asked participants to rate their responses to six statements on a five-point scale (e.g., 'I found out about e-services from my family and/or friends', 'My trust in the internet is largely influenced by the experiences of my family and/or friends') (see Appendix 1 for detail about social network measures for this study).

Regarding cultural orientations, we adopt the view that intra-cultural differences exist within a nation's culture (United Nations, 2016). For example, the study of Au (1999) found after testing the cultural means and intra-cultural variation (ICV) of 42 cultures that ICV is as large as the variation of cultural means across cultures. Given that Fiji is a multi-ethnic and multicultural society, we argue that cultural diversity affects citizens' e-government adoption behavior. To test the cultural orientations of our survey participants in Fiji, we adapted the instruments that Hofstede (2001) and House and coworkers (2004) used in their global surveys. For example, we used the question 'How important is it to you to socialize with your colleagues?' to measure participants' cultural orientation on MAS (masculinity versus femininity); and 'How important is it to you to follow rules, regulations and orders?' to measure UA (uncertainty avoidance) (see Appendix 2 for detail of the measures).

To survey participants' e-government adoption behavioral patterns, we drew on some of the popular instruments used in published research. For example, we adopted the instruments of Chuang et al. (2008) and Jaeger and Bertot (2010) to survey the kind of activities participants do when using e-government services. We also asked how frequently (ranging from ' 1 ' $=$ never to ' 5 ' $=$ very frequently) they had visited government websites (see Appendix 3 for detail of the measures).

A pilot survey was conducted to improve the clarity and effectiveness of the final survey's design and contents. A group of eight colleagues at a university in Fiji participated in the pilot survey, and provided constructive feedback. As a result, some of the questions used were re-worded, revised, and refined. The validity of the different constructs was also examined using the Cronbach's Alpha. All the scales used in the measurement were greater than 0.7 suggesting that our scales were valid (2018).

\subsection{Sample}

Our survey sample covered various geographical areas in Fiji in order to achieve a wide and valid representation of the population of Fiji. These areas were Suva, Nasinu, Nausori, Nadi, Lautoka, Ba, and Labasa, being the seven major cities and towns in which most Fijian citizens and residents live. Around 2,000 questionnaires were distributed randomly to Fijian adult citizens and residents in these areas by 25 research assistants from a university in Fiji who were recruited to administer the survey. The research assistants approached prospective participants mainly in areas where people congregate, such as 
Table 1

Summary of demographic data of survey participants $(N=749)$

\begin{tabular}{|c|c|c|}
\hline Variable & Valid frequency & \\
\hline Gender & Male: $47 \%$; Female: $49 \%$ & No answer, $4 \%$ \\
\hline Age & $\begin{array}{l}\text { Under } 20,12.7 \% ; 20-25,42 \% ; 26-30,16.7 \% ; 31-40,15 \% ; 41-50,6.4 \% ; 51-60 \text {, } \\
4.8 \% \text {; Over } 60,0.4 \%\end{array}$ & No answer, $2 \%$ \\
\hline Education & $\begin{array}{l}\text { Below high school, 1.6\%; High school, 15.9\%; Certificate/Diploma, 34\%; Bachelor's } \\
\text { degree, } 41 \% \text {; Master's degree, 5.2\%; Ph.D., 0.3\% }\end{array}$ & No answer, $2 \%$ \\
\hline Occupation & $\begin{array}{l}\text { Full-time student, 26\%; Part-time student, 14\%; Professional, 38\%; Factory worker, } \\
2 \% \text {; Farmer, } 2 \% \text {; Tradesperson, } 6 \% \text {; Currently unemployed, } 2 \%\end{array}$ & No answer, $10 \%$ \\
\hline
\end{tabular}

universities, government offices, businesses, and shopping centres, and collected a total of 749 completed questionnaires, representing a $37.5 \%$ response rate. The detail of the demographic background of the participants is summarized in Table 1 . There was a close balance between male (47\%) and female (49\%) participants (4\% not specifying a gender); the majority of the participants $(73.7 \%)$ were between 20 and 40 years old; $80.5 \%$ had completed tertiary-level education; $40 \%$ were students; and $38 \%$ were professionals.

\subsection{Statistical analysis}

To test our hypotheses, we employed various statistical analysis methods which are explained in the next section. The software we used for the data analysis was IBM SPSS Statistics 21.0.

\section{Results and discussion}

\subsection{Social networks and e-government adoption behavior}

In order to study whether and how social networks influence e-government adoption behavior, we followed a two-step procedure. First, we conducted a principal component analysis (PCA) of the 12 variables used for measuring e-government adoption behavioral patterns (see Appendix 3). Then, based on these results, we ran a regression analysis to examine the relationships between the two.

The results of PCA with Kaiser Normalization are shown in Appendix 4 due to their intermediate analysis nature. Three factors had eigenvalues greater than one. Hence, these three factors were retained for correlation analysis. In addition to the eigenvalue one criterion, scree plot criteria were used to make a decision on the number of factors to retain for the analysis. The scree plot graph was able to graph variables in a descending order. All the variables were retained for analysis that were to an inflection point (i.e. the point after which the scree plot graph starts to level off) (Wall et al., 2003; Costello \& Osborne, 2005). All twelve e-government adoption behavior variables (see Appendix 4) were loaded on the three components that were extracted during the PCA. The e-government adoption behavior variables were assigned to each component if their loading on that component was greater than 0.5. E-government adoption behavior component 1 , which was mostly related to obtaining government information from government websites, showed the strongest component, accounting for $27.9 \%$ variation in responses. E-government adoption behavior component 2, which is related to transacting with governments (e.g. applying for scholarships and government jobs on government websites), was the second most important component accounting for $19.6 \%$ variation in responses. E-government adoption behavior component 3 , which is mostly related to researching governments, was the third most important component accounting for $19.7 \%$ variation in responses. The Cronbach's $\alpha$ for components 1,2 and 3 was greater 
Table 2

Results of regression analysis: Social networks and e-government adoption behavior

\begin{tabular}{|c|c|c|c|c|c|c|c|c|c|}
\hline \multirow[t]{3}{*}{ Social network variables } & \multicolumn{3}{|c|}{$\begin{array}{l}{ }^{\wedge} \text { E-government adoption } \\
\text { component } 1\end{array}$} & \multicolumn{3}{|c|}{$\begin{array}{c}{ }^{\wedge} \text { E-government adoption } \\
\text { component } 2\end{array}$} & \multicolumn{3}{|c|}{$\begin{array}{l}{ }^{\wedge} \text { E-government adoption } \\
\text { component } 3\end{array}$} \\
\hline & \multicolumn{2}{|c|}{$\begin{array}{l}\text { Unstandardized } \\
\text { coefficients }\end{array}$} & \multirow{2}{*}{$\begin{array}{c}\begin{array}{c}\text { Standardized } \\
\text { coefficients }\end{array} \\
\beta\end{array}$} & \multirow{2}{*}{$\begin{array}{l}\text { Unstandardized } \\
\text { coefficients } \\
\beta\end{array}$} & \multicolumn{2}{|c|}{$\begin{array}{l}\text { Standardized } \\
\text { coefficients }\end{array}$} & \multirow{2}{*}{$\begin{array}{l}\begin{array}{c}\text { Unstandardized } \\
\text { coefficients }\end{array} \\
\beta\end{array}$} & \multicolumn{2}{|c|}{$\begin{array}{c}\text { Standardized } \\
\text { coefficients }\end{array}$} \\
\hline & $\beta$ & SE & & & SE & $\beta$ & & SE & $\beta$ \\
\hline E-service awareness via SNs & 0.021 & 0.036 & 0.027 & 0.070 & 0.037 & 0.090 & 0.003 & 0.037 & 0.004 \\
\hline $\begin{array}{l}\text { Decision to use or not to use } \\
\text { influenced by SN }\end{array}$ & 0.109 & 0.043 & $0.129^{*}$ & 0.080 & 0.044 & 0.093 & -0.055 & 0.043 & -0.065 \\
\hline $\begin{array}{l}\text { Information sharing among } \\
\text { SNs }\end{array}$ & -0.073 & 0.042 & -0.086 & -0.064 & 0.044 & -0.074 & 0.109 & 0.043 & $0.126^{*}$ \\
\hline $\begin{array}{l}\text { Seeking help from SN } \\
\text { members }\end{array}$ & 0.025 & 0.043 & 0.030 & -0.045 & 0.044 & -0.053 & 0.042 & 0.044 & 0.050 \\
\hline $\begin{array}{l}\text { Offering help to SN } \\
\text { members }\end{array}$ & 0.077 & 0.045 & 0.090 & -0.012 & 0.047 & -0.014 & 0.139 & 0.046 & $0.159^{* *}$ \\
\hline $\begin{array}{l}\text { Online trust influenced by } \\
\text { experience of SN } \\
\text { members }\end{array}$ & 0.105 & 0.046 & 0.121* & 0.105 & 0.047 & $0.119 *$ & -0.002 & 0.047 & -0.003 \\
\hline$R^{2}$ & & & 0.76 & & & 0.52 & & & 0.75 \\
\hline$F$ & & & $5.56^{* *}$ & & & $4.21^{* *}$ & & & $4.58^{* *}$ \\
\hline
\end{tabular}

Notes: ${ }^{*} p<0.05,{ }^{* *} p<0.01{ }^{\wedge}$ E-government Adoption Component 1 is related mostly to obtaining information from government websites. ${ }^{\wedge}$ E-government Adoption Component 2 is related mostly to transacting with governments on government websites. ${ }^{\wedge}$ E-government Adoption Component 3 is mostly concerning researching governments such as government policies.

than 0.7, indicating that the scale used for measuring the three components was internally consistent. According to Karamizadeh et al. (2013), the PCA based on orthogonal transformation is able to change the correlated values to linearly uncorrelated values. This study was a cross sectional study and involved collecting information on a mix of variables. We used PCA for variables that had common scale on the questionnaire. It was used because it enabled us to condense large quantities of similar scale data on each question to lower dimensions and simultaneously retain the most crucial information from the data set. Prior studies have demonstrated that with the use of the orthogonal components the data redundancy is kept to its minimum (Asadi et al., 2010).

Step two involved performing a multiple regression test. Our regression results (see Table 2) show that two social network variables, namely: (1) a decision to use or not use the Internet is influenced by social network members $(\beta=0.129, p<0.05)$; and (2) online trust exhibited by users is influenced by the experience of social network members $(\beta=0.121, p<0.05)$. These two variables are significant predictors of e-government adoption behavior component 1 (i.e. obtaining information).

Similarly, online trust influenced by experience of social network members $(\beta=0.119, p<0.05)$ has a statistically significant impact on e-government adoption behavior component 2 (i.e. transacting with governments). Finally, information sharing among social network members ( $\beta=0.126, p<0.05$ ) and offering help to social network members $(\beta=0.159, p<0.05)$ have a significant impact on egovernment adoption behavior component 3 (i.e. researching governments). These results are supportive of hypothesis H1, and suggest that social networks influence e-government adoption behavior in terms of decision-making, information sharing, offering help, and building trust. These results are also consistent with previous research. For example, a study by Alomari et al. (2014) suggested that citizens' use of e-government was influenced by their social connectivity and relationships with community members. Given that Fiji has a tight-knit community culture (Au, 1999), interactions within their social networks in these communities could play an important role in e-government adoption, as we have found. Moreover, the increasing popularity of Facebook in Fiji, observed by the authors when living there, makes it likely 
Table 3

Results of regression analysis: Cultural orientations and e-government adoption behavior

\begin{tabular}{|c|c|c|c|c|c|c|c|c|c|}
\hline \multirow{2}{*}{$\begin{array}{l}\text { Variables } \\
\text { Cultural orientation }\end{array}$} & \multicolumn{3}{|c|}{$\begin{array}{l}\text { E-government } \\
\text { adoption behavior } \\
\text { component } 1\end{array}$} & \multicolumn{3}{|c|}{$\begin{array}{c}\text { E-government } \\
\text { adoption behavior } \\
\text { component } 2\end{array}$} & \multicolumn{3}{|c|}{$\begin{array}{c}\text { E-government } \\
\text { adoption behavior } \\
\text { component } 3\end{array}$} \\
\hline & B & $\mathrm{SE}_{\mathrm{B}}$ & $\beta$ & $\mathrm{B}$ & $\mathrm{SE}_{\mathrm{B}}$ & $\beta$ & B & $\mathrm{SE}_{\mathrm{B}}$ & $\beta$ \\
\hline Socialize (MAS) & -0.003 & 0.033 & -0.004 & -0.038 & 0.033 & -0.053 & 0.021 & 0.032 & 0.029 \\
\hline Follow rules (UA) & -0.054 & 0.053 & -0.054 & -0.061 & 0.053 & -0.061 & 0.099 & 0.053 & $0.100^{*}$ \\
\hline Respect tradition (UA) & 0.034 & 0.056 & 0.033 & 0.075 & 0.056 & 0.073 & -0.071 & 0.055 & -0.070 \\
\hline Favor democratic system $(P D)$ & 0.067 & 0.053 & 0.070 & 0.078 & 0.053 & $0.092 *$ & 0.072 & 0.053 & 0.075 \\
\hline $\begin{array}{l}\text { Favor hierarchical administration } \\
\text { (PD) }\end{array}$ & 0.013 & 0.049 & 0.014 & 0.040 & 0.049 & 0.043 & 0.022 & 0.048 & 0.024 \\
\hline $\begin{array}{l}\text { Value teamwork more than individual } \\
\text { effort (INV) }\end{array}$ & 0.041 & 0.052 & 0.042 & -0.006 & 0.052 & -0.006 & -0.023 & 0.051 & -0.024 \\
\hline Take risks and make changes (UA) & 0.014 & 0.051 & 0.014 & 0.018 & 0.051 & 0.018 & 0.030 & 0.051 & 0.029 \\
\hline lance (MAS) & -0.065 & 0.052 & -0.066 & -0.029 & 0.051 & -0.030 & -0.070 & 0.051 & -0.072 \\
\hline Set long-term goals (LTO) & -0.021 & 0.064 & -0.019 & -0.052 & 0.064 & -0.048 & -0.009 & 0.063 & -0.008 \\
\hline $\begin{array}{l}\text { Concern about environmental issues } \\
(\mathrm{FO})\end{array}$ & $\mathbf{0 . 1 3 4}$ & 0.055 & $\mathbf{0 . 1 3 0}^{* *}$ & 0.078 & 0.055 & 0.077 & 0.078 & 0.055 & 0.075 \\
\hline $\begin{array}{l}\text { Continuously improve work } \\
\text { performance (PO) }\end{array}$ & -0.029 & 0.066 & -0.026 & & 0.066 & -0.020 & 0.008 & 0.065 & 0.008 \\
\hline $\begin{array}{l}\text { Embrace latest technology quickly } \\
(\mathrm{FO})\end{array}$ & -0.040 & 0.051 & -0.042 & & 0.051 & 0.046 & 0.108 & 0.050 & $0.112^{* *}$ \\
\hline$R^{2}$ & & 0.862 & & & 0.774 & & & 0.695 & \\
\hline$F$ & & $4.75^{* *}$ & & & $5.22^{* *}$ & & & $5.62^{* *}$ & \\
\hline
\end{tabular}

Note: ${ }^{*} p<0.05,{ }^{* *} p<0.01$.

that the influence of social networks on e-government use will soon get much stronger. It should be noted that trust (i.e., 'My trust in the internet is often influenced by the experience of my family/friends') was found to be a salient factor in e-government adoption in particular when it comes to transacting with governments. The empirical study of Kurfali et al. (2017) found that trust of Internet derived from social influence has a positive impact on behavioral intention to use e-government services. In this regard, harnessing the value and trust gained from social networks can be crucial to increasing e-government adoption.

\subsection{Cultural orientations and e-government adoption}

To test $\mathrm{H} 2 \mathrm{a}-\mathrm{H} 2 \mathrm{~g}$ concerning the relationship between cultural orientations and e-government adoption behavior, we ran a multiple regression analysis of e-government adoption behavior, using e-government adoption behavior components 1,2, and 3 that we obtained from the PCA (see Appendix 4 for detail), and cultural orientations. The regression results (Table 3) suggest that some cultural orientations (i.e., PD, FO, PO) can significantly predispose toward a particular e-government adoption behavior. For example, 'favoring a democratic system' (an indication of low PD cultural orientation) positively affected transacting with governments using government websites (i.e. e-government adoption behavior component 2). These results support hypotheses $\mathrm{H} 2 \mathrm{a}, \mathrm{H} 2 \mathrm{f}$, and $\mathrm{H} 2 \mathrm{~g}$, and are consistent with studies by Zhao et al. (2014) and Khalil (2011). More importantly, our results show not only whether cultural orientations affect e-government adoption behavior, but also how they affect them (i.e., which cultural orientation affects which e-government adoption behavior). Examining the effect of each of the cultural orientations on the adoption pattern individually could help better understand cultural issues in detail and enable e-government providers to focus their resources on improving specific areas of e-government design and contents. 


\section{Theoretical contributions and practical implications}

\subsection{Theoretical contributions and implications}

This study has contributed to the existing theories and literature on e-government adoption research mainly in three ways. Firstly, to the best of our knowledge, this is the first study of its kind that examines how social networks, along with cultural orientations, influence e-government adoption behavior. The extant e-government adoption research using the UTAUT model has identified the social influence on citizens' adoption behavior in a broad term. However, the findings of our study pinpoint the specific aspects of the social influence on adoption, suggesting that social cognition in the form of social learning through information and experience exchanges among social network members plays a significant role in e-government adoption behavior.

Secondly, our study has identified empirically the influence of traditional (offline) social networks on e-government adoption in the particular case of Fiji, where Internet penetration is still low and online social media are not yet widely used. However, with the increasing popularity of social media such as Facebook and Twitter in many countries including developing countries, in the not far future, the Fijian government will have to adopt progressively Government 2.0 as what governments in many countries have done, which involves social media with web 2.0 technologies. While research on social media and e-government adoption is growing (e.g., Kane et al., 2014), little empirical research has been undertaken, from a social network perspective, on the interfaces between offline social networks and online communities via social media and their effects on e-government adoption behavior. Our study may help with this line of inquiry.

Thirdly, the results of our study address the knowledge gap in the extant world e-government literature which has paid limited attention to PICs (Cullen \& Hassall, 2017). In addition to the differences of PICs from non-PICs in terms of economic status (e.g. small markets), geographic isolation (e.g. small islands) and political/legal systems (e.g. transition from chief authority to modern and democratic governance), the social structure and cultural background of PICs are also distinct. By taking social network and cultural perspectives, our research model should aid in developing a more robust conceptual model for future research into PICs' e-government adoption.

\subsection{Practical implications}

This study has also practical implications. Firstly, as indicated in our findings, social networks can influence e-government adoption behavior in various ways. In this regard, it appears to us that the Fijian government could utilize informal social networks to promote e-government services. For example, when introducing new e-government services, governments may consider using word-of-mouth tactics to get their message across social networks. In today's Fiji, studies indicate that Fijian citizens continue to use their personal social networks (family, friends and friends' friends) to get access to over-thecounter government services. For some, using their personal social networks allows them to bypass formal bureaucracies of government departments (Cullen \& Hassall, 2017). This traditional practice could be reduced by improving the efficiency, integrity and transparency of e-government services. Secondly, our findings show that the influence of social networks on online trust is a significant determinant in e-government adoption. Citizens must have confidence in both the government and the enabling technologies if they are to increase their use of e-government services. To help build the online trust, the Fiji Government must ensure the privacy of citizens through relevant laws and government conduct. In addition, given the importance of social networks in which both positive and negative experiences can be 
shared with others, e-government providers should adopt a citizen-centric approach to enhancing users' experience in all aspects of their e-services, in terms of both technology and quality of contents. Thirdly, the findings of our study also suggest that cultural orientations affect e-government adoption behavior. In this regard, e-government service providers may need to consider cultural orientations when engaging users in a social interaction setting, for instance, when targeting community-based social networking sites to engage in e-consultation with their citizens.

\section{Limitations and future research}

Notwithstanding the contributions made by this study, it also has limitations. First, for this study, we limited social networks to the individual level, namely, families and friends because, in the context of Fiji, they are considered the most important (Cato, 1955). However, as discussed in the preceding section, a social network can be composed of a multitude of individual, institutional and societal networks (nodes) and the links between them. To identify and measure the configuration, strength, and direction of each of the links and their influences on e-government adoption is beyond the scope of the present paper. Future research, though, could tackle this limitation and examine in greater detail the configurations and links that play the most important role in regard to e-government adoption. Such a study could be of great value. Second, concerns have been raised regarding cultural research that assumes there is a simple linear relationship between culture and other factors (Tung \& Verbeke, 2010). We have attempted to address such concerns by examining the influence of social networks along with cultural orientation on e-government adoption. However, given the focus of the study we were unable to explore empirically other potential factors at individual and national levels that may affect e-government adoption. At the individual level, for example, self-efficacy could be a salient factor in Internet use (Douglas, 1978) and the uptake of e-government (Hung et al., 2013). At the national level, ICT infrastructure, economic growth, the political system and regime, and a country's legal system could be important factors influencing e-government adoption (e.g. Zhao et al., 2014). Future research could usefully take a multidimensional and integrative approach to explore the multitude of influences on e-government adoption and behavioral patterns.

\section{Conclusions}

This study seeks to investigate the relationships between network ties, cultural orientations, and egovernment adoption behavior. For that purpose, we developed and tested a research model built on social network theory and cultural models. The combination of the two theoretical perspectives offers new insights into e-government adoption behavior in the extant literature. Our model proved to be empirically viable and useful to explain how social networks along with cultural orientations influence e-government adoption behavior. With the increasing popularity of online social networks such as Facebook and LinkedIn, the influence of social networks on e-government adoption, whether online or in a traditional way, warrants further research.

\section{References}

Abdullah, A.B., Ling, K.S., \& Samad, Z. (2008). The relationship between national culture and e-adoption: a case study of Iran. American Journal of Applied Sciences, 5(4), 369-377. 
Adler, P.S., \& Kwon, S.W. (2002). Social capital, Prospects for a new concept. Academy of Management Review, 27(1), 17-40. Adu, K.K., Patrick, N., Park, E.G., \& Adjei, E. (2017). Evaluation of the implementation of electronic government in Ghana. Information Polity, (Preprint), 1-14.

Alcaide-Muñoz, L., \& Rodríguez Bolívar, M.P. (2015). Understanding e-government research: A perspective from the information and library science field of knowledge. Internet Research, 25(4), 633-673.

Al-Hujran, O., Al-Debei, M.M., Chatfield, A., \& Migdadi, M. (2015). The imperative of influencing citizen attitude toward e-government adoption and use. Computers in Human Behavior, 53, 189-203.

Alomari, M.K., Sandhu, K., \& Woods, P. (2014). Exploring citizen perceptions of barriers to e-government adoption in a developing country. Transforming Government, 8(1), 131-150.

Asadi, S., Rao, C.D.S., \& Saikrishna, V. (2010). A comparative study of face recognition with principal component analysis and cross-correlation technique. International Journal of Computer Applications, 10(8), 0975-8887.

$\mathrm{Au}$, K.Y. (1999). Intra-cultural variation: Evidence and implications for international business. Journal of International Business Studies, 30(4), 799-812.

Axford, B., \& Huggins, R. (2003). Towards a political sociology of the Internet and local governance. Telematics and Informatics, 20, 185-192.

Aykut, A. (2007). Cross-cultural analysis of European e-government adoption. World Applied Sciences Journal, 7(9), 11241130.

Bélanger, F., \& Carter, L. (2012). Digitizing government interactions with constituents: An historical review of e-government research in information systems. Journal of Association for Information System, 13(5), 363-394.

Borgatti, S.P., \& Cross, R. (2003). A relational view of information seeking and learning in social networks. Management Science, 49(4), 432-445.

Borgatti, S.P., \& Halgin, D.S. (2011). On network theory. Organization Science, 22(5), 1168-1181.

Borgatti, S.P., Mehra, A., Brass, D.J., \& Labianca, G. (2009). Network Analysis in the Social Sciences. Science, 323(5916), 892-895.

Burt, R.S. (1987). Social contagion and innovation: Cohesion versus structural equivalence. American Journal of Sociology, 92, 1287-1335.

Carter, L., \& Bélanger, F. (2005). The utilization of e-government services: citizen trust, innovation and acceptance factors. Information Systems Journal, 15(1), 5-25.

Castells, M. (2011). The information age: Economy, society, and culture - Vol. 1: The rise of the network society. Chichester, West Sussex: John Wiley \& Sons.

Cato, A.C. (1955). Fijians and Fiji-Indians: A culture-contact problem in the South Pacific. Oceania, 26(1), 14-34.

Chow, W.S., \& Chan, L.S. (2008). Social network, social trust, and shared goals in organizational knowledge sharing. Information \& Management, 45(7), 458-465.

Chuang, S.C., Lin, F.M., \& Tsai, C.C. (2015). An exploration of the relationship between Internet self-efficacy and sources of Internet self-efficacy among Taiwanese university students. Computers in Human Behavior, 48, 147-155.

Costello, A.B., \& Osborne, J.W. (2005). Best practices in exploratory factor analysis: Four recommendations for getting the most from your analysis. Practical Assessment, Research \& Evaluation, 10(7), 1-9.

Cullen, R., Hassall, G., eds. (2017). "E-Government in Pacific Island Countries." In Achieving Sustainable E-Government in Pacific Island States, 3-32. New York: Springer International.

Davis, F.D. (1989). Perceived usefulness, perceived ease of use, and user acceptance of information technology. Management Information Systems Quarterly, 13(3), 319-340.

Douglas, M. (1978). Cultural bias. London: Royal Anthropological Institute.

Emirbayer, M., \& Goodwin, J. (1994). Network analysis, culture, and the problem of agency. American Journal of Sociology, 99(6), 1438, 1411-1454.

Fiji Bureau of Statistics. (2014). Factsheet on Fiji government expenditure. Suva, Fiji: Fiji Bureau of Statistics.

Ford, D.P., Connelly, C.E., \& Meister, D. (2009). Hofstede's Dimensions of National Culture in IS Research. In: Dwivedi, Y., eds. Handbook of Research on Contemporary Theoretical Models in Information Systems. Hershey, PA: IGI Global, pp. 455-481.

Fountain, J.E. (2001). Building the virtual state: Information technology and institutional change. Washington, D.C.: Brookings Institution Press.

Fountain, J. (2005). Central issues in the political development of the virtual state. In: Castells, M., Cardoso, G., eds. The Network Society: From Knowledge to Policy. Washington, D.C.: Center for Transatlantic Relations, pp. 149-169.

Frambach, R.T., \& Schillewaert, N. (2002). Organizational innovation adoption: A multi-level framework of determinants and opportunities for future research. Journal of Business Research, 55(2), 163-176.

Freeman, L. (2004). The development of social network analysis: A study in the sociology of science. Vancouver, BC: Empirical Press.

Feeney, M.K., \& Welch, E.W. (2016). Technology-task coupling: Exploring social media use and managerial perceptions of e-government. The American Review of Public Administration, 46(2), 162-179. 
Hill, R., Beynon-Davies, P., \& Williams, M.D. (2008). Older people and Internet engagement: Acknowledging social moderators of Internet adoption, access and use. Information Technology \& People 21(3), 244-266.

Hofstede, G. (2001). Cultures and organizations: Software of the mind. New York: McGraw-Hill.

Hofstede, G., Hofstede, G.J., \& Minkov, M. (2010). Cultures and organizations: Software of the mind-Intercultural cooperation and its importance for survival. p6. New York: McGraw-Hill.

Hofstede Centre. (2012). National culture: Fiji. Viewed 15 January 2015, from http://geert-hofstede.com/Fiji.html.

House, R.J., Javidan, M., Dorfman, P.W., \& Gupta, V. (2004). Culture, leadership, and organizations: The GLOBE study of 62 societies. Thousand Oaks, CA: SAGE Publications.

Howard, M.C., \& McKim, P.C. (1983). Contemporary Cultural Anthropology, Toronto: Littel, Brown \& Company.

Hung, S.Y., Chang, C.M., \& Kuo, S.R. (2013). User acceptance of mobile e government services: An empirical study. Government Information Quarterly, 30(1), 33-44.

Imran, A., \& Gregor, S. (2010). Uncovering the hidden issues in e-government adoption in a least developed country: the case of Bangladesh. Journal of Global Information Management, 18(2), 30-56.

Inglehart, R., \& Welzel, C. (2005). Modernization, cultural change, and democracy: The human development sequence. New York: Cambridge University Press.

Institute of Digital Research and Education. (2018). What Does Cronbach's Alpha Mean: SPSS FAQ. Retrieved from: https://stats.idre.ucla.edu/spss/faq/what-does-cronbachs-alpha-mean/.

Jaeger, P.T., \& Bertot, J.C. (2010). Designing, implementing, and evaluating user-centered and citizen-centered e-government. International Journal of Electronic Government Research, 6(2), 1-17.

Jones, M.L. (2007). Hofstede-Culturally questionable [online]? Faculty of Commerce, University of Wollongong. Available from: http://ro.uow.edu.au/commpapers/370 [10 July 2009].

Kadushin, C. (2012). Understanding social networks: Theories, concepts, and findings. Oxford University Press.

Kamal, M.M., Hackney, R., \& Sarwar, K. (2013). Investigating Factors Inhibiting e-Government Adoption in Developing Countries: The Context of Pakistan. Journal of Global Information Management, 21(4), 77-102.

Kamoun, F., \& Almourad, M.B. (2014). Accessibility as an integral factor in e-government web site evaluation: The case of Dubai's e-government. Information Technology \& People, 27(2), 208-228.

Karamizadeh, S., Abdullah, S.M., Manaf, A.A., Zamani, M., \& Hooman, A. (2013). An overview of principal component analysis. Journal of Signal and Information Processing, 4(3), 173.

Kane, G.C., Alavi, M., Labianca, G.J., \& Borgatti, S. (2014). What's different about social media networks? A framework and research agenda. MIS Quarterly, 38(1), 275-304.

Khalil, O.E. (2011). E-government readiness: Does national culture matter? Government Information Quarterly, 28(3), 388399.

Kurfali, M., Arifoğlu, A., Tokdemir, G., \& Paçin, Y. (2017). Adoption of e-government services in Turkey. Computers in Human Behavior, 66, 168-178.

Lal, B. (2013). Trajectories of transformation: Fiji Indians from common roll to consociationalism. Diaspora Studies, 5(2), 147-169.

Lean, O.K., Zailani, S., Ramayah, T., \& Fernando, Y. (2009). Factors influencing intention to use e-government services among citizens in Malaysia. International Journal of Information Management, 29(6), 458-475.

Maertens, A., \& Barrett, C.B. (2013). Measuring social networks' effects on agricultural technology adoption. American Journal of Agricultural Economics, 95(2): 353-359.

Morgan, D.L., \& Rytina, S. (1977). Comment on 'Network sampling: Some first steps' by Mark Granovetter. American Journal of Sociology, 83, 722-727.

Nohria, N., \& Eccles, R. (2000). Face-to-face: Making network organizations work. Technology, Organizations and Innovation: Critical Perspectives on Business and Management: 1659-1681.

Norris, D.F., \& Moon, M.J. (2005). Advancing e-government at the grassroots: Tortoise or hare? Public Administration Review, 65(1), 64-75.

Pachucki, M.A., \& Breiger, R.L. (2010). Cultural holes: Beyond relationality in social networks and culture. Annual Review of Sociology, 36, 205-224.

Phillips, P.J., Flynn, P.J., Scruggs, T., Bowyer, K.W., Chang, J., Hoffman, K., \& Worek, W. (2005). Overview of the face recognition grand challenge. In Computer Vision and Pattern Recognition, CVPR 2005. IEEE Computer Society Conference on (Vol. 1, pp. 947-954). IEEE.

Porumbescu, G.A. (2016). Comparing the Effects of E-Government and Social Media Use on Trust in Government: Evidence from Seoul, South Korea. Public Management Review, 18(9), 1308-1334.

Rabaa'i, A.A. (2017). The use of UTAUT to investigate the adoption of e-government in Jordan: a cultural perspective. International Journal of Business Information Systems, 24(3), 285-315.

Rogers, E.M. (1995). Diffusion of innovations (4th ed.). New York: The Free Press.

Sivakumar, K., \& Nakata, C. (2001). The stampede toward Hofstede's framework: Avoiding the sample design pit in crosscultural research. Journal of International Business Studies, 32, 555-574. 
Scott, J. (2012). Social network analysis (3rd ed.). London: Sage.

Simmel, G. (2009). Sociology: Inquiries into the construction of social forms. Leiden, Netherlands: Brill.

Tichy, N.M., Tushman, M.L., \& Fombrun, C. (1979). Social network analysis for organizations. Academy of Management Review, 4(4), 507-519.

Trompenaars A., \& Hampden-Turner, C. (2000). Riding the waves culture: Understanding cultural diversity in business (2nd ed.). London: Nicholas Brealey Pub.

Tung, R.L., \& Verbeke, A. (2010). Beyond Hofstede and GLOBE: Improving the quality of cross-cultural research. Journal of International Business Studies, 41(8), 1259-1274.

United Nations. (2016). The United Nations E-Government Survey 2016: E-Government in Support of Sustainable Development, Viewed 11 October 2016, from https://publicadministration.un.org/egovkb/en-us/Reports/UN-E-GovernmentSurvey-2016.

Valente, T.W. (1996). Social network thresholds in the diffusion of innovations. Social Networks, 18(1), 69-89.

Venkatesh, V., Morris, M.G., Davis, G.B., \& Davis, F.D. (2003). User acceptance of information technology: Toward a unified view. MIS Quarterly, 27(3), 425-478.

Vicente, M.R., \& Novo, M. (2014). An empirical analysis of e-participation: The role of social networks and e-government over citizens' online engagement. Government Information Quarterly, 31(3), 379-387.

Wadley, G., Bumpus, A., \& Green, R. (2014). Citizen involvement in the design of technology for climate change adaptation projects in the Pacific. Paper presented at $O z C H I$ 2015: Being human, Melbourne, Australia, 7-10 December. Available from http://people.eng.unimelb.edu.au/gwadley/pubs/OzCHI2014-ClimateChange.pdf.

Wall, M.E., Rechtsteiner, A., \& Rocha, L.M. (2003). Singular value decomposition and principal component analysis. In $A$ practical approach to microarray data analysis (91-109). Springer, Boston, MA.

Wallis, J. (2014). Australia's changing strategic interests in the South Pacific. The University of Nottingham. Available from https://blogs.nottingham.ac.uk/chinapolicyinstitute/2014/02/05/australias-changing-strategic-interests-in-the-southpacific/.

Wasserman, S., \& Faust, K. (1994). Social network analysis: Methods and applications. New York: Cambridge University Press.

Williams, K., \& Durrance, J.C. (2008). Social Networks and Social Capital: Rethinking theory in Community Informatics. The Journal of Community Informatics, 4(3), Accessed online 13.9.16 from http://ci-journal.net/index.php/ciej/article/view/ 465/430.

World Bank. (2008). Definition of e-government. Available from http://web.worldbank.org/wbsite/external/topics/extinformati onandcommunicationandtechnologies/extegovernment/0,contentMDK:20507153 menuPK:702592 pagePK:148956 piPK:216618 theSitePK:702586,00.html.

Yildiz, M. (2007). E-government research: Reviewing the literature, limitations, and ways forward. Government Information Quarterly, 24(3), 646-665.

Zhang, H., Xu, X., \& Xiao, J. (2014). Diffusion of e-government: A literature review and directions for future directions. Government Information Quarterly, 31(4), 631-636.

Zhang, X., \& Maruping, L.M. (2008). Household technology adoption in a global marketplace: Incorporating the role of espoused cultural values. Information Systems Frontiers, 10(4), 403-413.

Zhao, F. (2013). An empirical study of cultural dimensions and e-government development: Implications of the findings and strategies. Behaviour and Information Technology, 32(3), 294-306.

Zhao, F., Shen, K.N., \& Collier, A. (2014). Effects of national culture on e-government diffusion: A global study of 55 countries. Information \& Management, 51(8), 1005-1016.

\section{Appendix}

Appendix 1

Social networks measures

Social network measures

E-service awareness via social networks

Decision to use or not to use Internet influenced by social networks

Information sharing among social network members

Seeking help from social network members

Offering help to social network members

Online trust influenced by experience of other social network members 
Appendix 2

Concepts and measures of cultural orientations of Hofstede and the GLOBE

\begin{tabular}{|c|c|c|}
\hline Cultural orientations & Concepts* & Measures $^{* *}$ \\
\hline Power distance (PD) & $\begin{array}{l}\text { The extent to which a society accepts the fact that } \\
\text { power in institutions and organizations is } \\
\text { distributed unequally. }\end{array}$ & $\begin{array}{l}\text { Favor democratic system } \\
\text { Favor hierarchical administration }\end{array}$ \\
\hline $\begin{array}{l}\text { Uncertainty avoidance } \\
\text { (UA) }\end{array}$ & $\begin{array}{l}\text { The extent to which members of a society feel } \\
\text { uncomfortable in ambiguous and uncertain } \\
\text { situations and take actions to avoid them. }\end{array}$ & $\begin{array}{l}\text { Respect tradition } \\
\text { Follow rules } \\
\text { Take risks and make changes }\end{array}$ \\
\hline $\begin{array}{l}\text { Individualism vs. } \\
\text { collectivism (IDV) }\end{array}$ & $\begin{array}{l}\text { The extent to which individuals are supposed to } \\
\text { look after themselves or remain integrated into } \\
\text { groups. }\end{array}$ & $\begin{array}{l}\text { Value teamwork more than individual } \\
\text { effort }\end{array}$ \\
\hline $\begin{array}{l}\text { Masculinity vs. femininity } \\
\text { (MAS) }\end{array}$ & $\begin{array}{l}\text { It refers to the distribution of emotional roles } \\
\text { between the genders. It contrasts 'tough' } \\
\text { masculine with 'tender' feminine societies. }\end{array}$ & $\begin{array}{l}\text { Socialize with others } \\
\text { Value work-life balance }\end{array}$ \\
\hline $\begin{array}{l}\text { Long-term vs. short-term } \\
\text { orientation (LTO) }\end{array}$ & $\begin{array}{l}\text { The extent to which a culture programs its } \\
\text { members to accept delayed satisfaction of their } \\
\text { material, social, and emotional needs. }\end{array}$ & Set long-term goals \\
\hline $\begin{array}{l}\text { Performance orientation } \\
\text { (PO) }\end{array}$ & $\begin{array}{l}\text { The extent to which an organization or society } \\
\text { encourages and rewards group members for } \\
\text { performance improvement and excellence. }\end{array}$ & $\begin{array}{l}\text { Continuously improve work } \\
\text { performance }\end{array}$ \\
\hline Future orientation (FO) & $\begin{array}{l}\text { The degree to which individuals in organizations } \\
\text { or societies engage in future-oriented behaviors } \\
\text { such as planning, investing in the future, and } \\
\text { delaying gratification. }\end{array}$ & $\begin{array}{l}\text { Concern about environmental issues } \\
\text { Embrace latest technology quickly }\end{array}$ \\
\hline
\end{tabular}

Notes: ${ }^{*}$ The concepts of PD, UA, IDV, MAS, and LTO were taken from Hofstede (2001) those of PO and FO were from the GLOBE (House et al., 2004). ${ }^{* *}$ The measures were taken from the survey instruments used by Hofstede (2001) and the GLOBE (House et al., 2004).

Appendix 3

E-government adoption measures

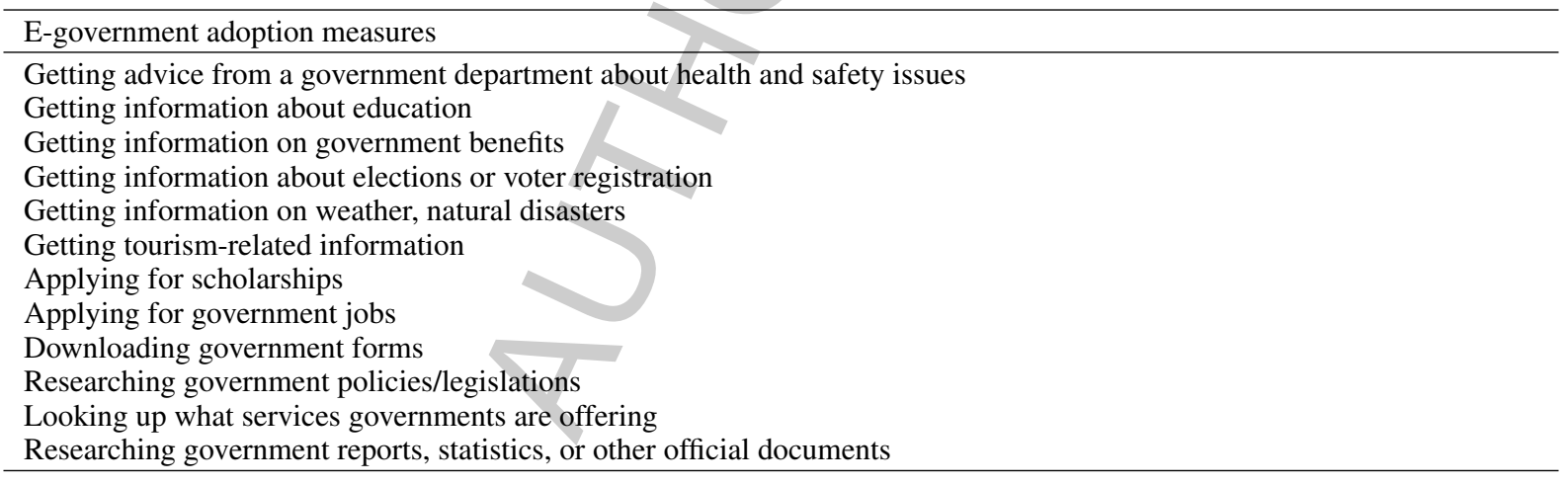


Appendix 4

Principal component analysis for e-government adoption behavior

\begin{tabular}{lcc}
\hline E-government adoption behavior variables & \multicolumn{2}{c}{ E-government adoption component } \\
\cline { 2 - 3 } & \multicolumn{1}{c}{3} \\
\hline Getting advice from a government department about health and safety issues & 0.850 & \\
Getting information about education & 0.808 & \\
Getting information on government benefits & 0.707 & \\
Getting information about elections or voter registration & 0.687 & \\
Getting information on weather, natural disasters & 0.630 & \\
Getting tourism-related information & 0.568 & \\
Applying for scholarships & & 0.822 \\
Applying for government jobs & & 0.766 \\
Downloading government forms & & 0.606 \\
Researching government policies/legislations & & 0.823 \\
Looking up what services governments are offering & & 0.687 \\
Researching government reports, statistics, or other official documents & & 0.561 \\
Cronbach's $\alpha$ & 0.715 & 0.757 \\
Initial eigenvalues & 5.742 & 1.175 \\
Variance explained (\%) & 27.891 & 19.616 \\
\hline
\end{tabular}

Note: Extraction method = principal component analysis. Rotation method = Varimax with Kaiser normalization. Rotation converged in 5 iterations. 